\section{Performance of Adafuel and Adarcias as Peach Rootstocks}

\author{
M.A. Moreno, M.C. Tabuenca, and R. Cambra \\ Departamento de Pomología, Estación Experimental de Aula Dei (Consejo \\ Superior de Investigaciones Científicas), Apartado 202, 50080 Zaragoza, \\ Spain
}

Additional index words. Prunus amygdalo-persica, Prunus persica, vigor, yield, productivity, fruit weight

\begin{abstract}
Field performance of several peach $\mathrm{x}$ almond hybrid [Prunus amygdalo-persica (West) Redh.] rootstocks grafted with different peach cultivars [Prunus persica (L.) Batsch] were tested for 11 to 12 years in three experiments. 'Loadel' scions were grafted on Adafuel, Adarcias, Albatarrech, Calanda, and GF 677 hybrids. 'Catherina' and 'Flavortop' scions were grafted on Adafuel, Adarcias, and GF 677 hybrids. Adafuel was the most invigorating rootstock for 'Loadel', after the 12 years of scion growth, but Adarcias also promoted higher scion productivity than other peach $x$ almond hybrid rootstocks. Although there were no differences in 'Catherina' productivity when grafted on different rootstocks, this cultivar and 'Flavortop' grafted on Adarcias showed the least vigor. 'Flavortop' on Adafuel had more vigor than on the other rootstocks. According to our results, Adafuel (a vigorous rootstock) seems to be suitable for peach production in low nutrient and calcareous soils unfavorable for peach seedling rootstocks. Adarcias seems promising as a peach rootstock for avoiding excessive scion growth, and it may be useful where tree size needs to be controlled.
\end{abstract}

Many peach orchard sites in Mediterranean countries have calcareous soils with high $\mathrm{pH}$. On these sites, the ordinary peach seedling rootstock tends to develop lime-induced Fe chlorosis due to low Fe availability, a condition that reduces cropping efficiency. Peach $\mathrm{x}$ almond hybrids repeatedly have been reported to be tolerant to alkaline soil conditions (Almaliotis et al., 1993; Bernhard and Grasselly, 1959, 1981; Egilla and Byrne, 1989; Syrgiannidis, 1985). They are generally graft compatible with peach and almond and induce vigorous growth. They are recommended when planting on poor and lime soils or under replanting conditions (Bernhard and Germain, 1975; Cambra, 1990; Kester and Asay, 1986); however, peach $\mathrm{x}$ almond hybrids can be excessively invigorating (Guerriero etal., 1988; Loreti et al., 1989).

Since 1970, the Estación Experimental de Aula Dei (EEAD) (Consejo Superior de Investigaciones Científicas), Zaragoza, Spain, has engaged in a rootstock breeding program to obtain successful peach $\mathrm{x}$ almond hybrids. Adafuel (Cambra, 1990), Adarcias (Moreno and Cambra, 1994), Albatarrech, and Calanda

Received for publication 13 Dec. 1994. Accepted for publication 18 May 1994. Financial support was provided by Comisión Asesora de Investigación Científica y Técnica project PR84-0180, Comisión Interministerial de Ciencia y Tecnología projects AGR88-0074 and AGR91-0434. M.A.M. was supported by Consejo Asesor de Investigación de la Diputación General de Aragón and Consejo Superior de Investigaciones Científicas. We thank A. Blanco and A.M. Casas for critical reading and translation of this manuscript. The cost of publishing this paper was defrayed in part by the payment of page charges. Under postal regulations, this paper therefore must be hereby marked advertisement solely to indicate this fact. are such hybrids and were selected from nonselected seedling populations originating from various regions of Spain. These hybrids have good rooting ability as hardwood cuttings and good compatibility in the nursery with all tested peach cultivars. In this study, we present the performance of these hybrids tested as rootstocks with three peach cultivars.

\section{Materials and Methods}

Trials were performed at the EEAD in plots of alkaline soil $(\mathrm{pH}=8)$ with a high content of total $(30 \%)$ and active $(11 \%) \mathrm{CaCO}_{3}$.

'Loadel' peach was grafted in situ in Sept. 1981 on Adafuel, Adarcias, Albatarrech, and Calanda peach $\mathrm{x}$ almond hybrids; 'Catherina' and 'Flavortop' were grafted on Adafuel and Adarcias peach $x$ almond hybrids in Apr. 1983. In all the trials, GF 677 was used as a control because it is the most commonly used peach $\mathrm{X}$ almond hybrid rootstock in Mediterranean countries. The orchards were planted at $5 \times 5 \mathrm{~m}$ for 'Loadel' and $6 \times 5 \mathrm{~m}$ for the two other cultivars. The orchard was managed following the usual local procedures, including flood irrigation.

Trees were placed in a randomized comduring the first 12 years in the orchard.

${ }^{\mathrm{z}}$ Mean separation within columns at $P \leq 0.05$. plete-block design with five single-tree replications for each rootstock-scion combination. Guard rows were used to preclude edge effects.

During the cropping years, trunk circumference, yield, and number of fruit per tree were recorded. Trunk circumference was determined each dormant season at $10 \mathrm{~cm}$ above the graft union. Fruit were left unthinned to obtain full potential production. Mean fruit weight, cumulative yields per tree, and the yield efficiency [cumulative kilogram per tree per trunk cross-sectional area (TCSA)] of each rootstock were obtained.

TCSA and cropping data for all graft combinations were evaluated by analysis of variance. The data were analyzed using the SPSS program (Norusis, 1986). Means were separated by Fisher's (protected) LSD at $P \leq 0.05$ when the $\mathrm{F}$ test was significant. Correlation coefficients $(r)$ were calculated for mean fruit weight, crop load, and tree vigor.

\section{Results}

The effects of rootstock on tree growth, expressed as TCSA of each cultivar, mean fruit weight (1988 to 1993), yield, cumulative yield, and yield efficiency were statistically significant.

Yields of all cultivars in 1987 and 1990 were severely reduced by spring frosts. 'Loadel' production also was reduced by frosts in Spring 1991 and 1993. Similarly, 'Flavortop' was damaged in 1993, although the damage was less severe. Yield efficiency was strongly affected because of the sharp yield decrease caused by spring frosts and an increase in TCSA, as vigor is affected by fruit production level (Proebsting, 1958).

'Loadel'. For 'Loadel' (Table 1), TCSA was significantly smaller when grafted on Adarcias compared to Adafuel and GF 677. By the 12th year of scion growth, vigor (expressed by TCSA) of 'Loadel' grafted on Adarcias was reduced by $29 \%$ and $17 \%$ compared to Adafuel and GF 677, respectively. Differences among Adarcias, Albatarrech, and Calanda were nonsignificant. Adafuel was the most invigorating rootstock. There were no differences among rootstocks in precocity. During the three first cropping years, there were no rootstock effects on yield (Fig. 1). However, cumulative production by the 12th year of scion growth was significantly greater for the trees grafted on Adarcias and GF 677 than for those on Adafuel, Albatarrech, and Calanda. Also, the productivity of 'Loadel'

Table 1. Rootstock effects on trunk cross-sectional area (TCSA) and yield characteristics of 'Loadel' peach

\begin{tabular}{|c|c|c|c|c|}
\hline Rootstock & $\begin{array}{c}\text { TCSA } \\
\left(\mathrm{cm}^{2}\right)\end{array}$ & $\begin{array}{c}\text { Cumulative } \\
\text { production } \\
(\mathrm{kg} / \text { tree })\end{array}$ & $\begin{array}{c}\text { Yield } \\
\text { efficiency } \\
\left(\mathrm{kg} \cdot \mathrm{cm}^{-2}\right)\end{array}$ & $\begin{array}{l}\text { Mean } \\
\text { fruit wt } \\
\quad(\mathrm{g})\end{array}$ \\
\hline Adafuel & $446 c^{2}$ & $293 \mathrm{a}$ & $0.66 \mathrm{a}$ & $128 \mathrm{ab}$ \\
\hline Adarcias & $317 \mathrm{a}$ & $394 \mathrm{~b}$ & $1.25 \mathrm{c}$ & $122 \mathrm{a}$ \\
\hline Albatarrech & $338 \mathrm{ab}$ & $294 \mathrm{a}$ & $0.87 \mathrm{ab}$ & $139 \mathrm{c}$ \\
\hline Calanda & $358 \mathrm{ab}$ & $295 \mathrm{a}$ & $0.82 \mathrm{ab}$ & $136 \mathrm{bc}$ \\
\hline GF 677 & $380 \mathrm{~b}$ & $390 \mathrm{~b}$ & $1.03 \mathrm{~b}$ & $123 \mathrm{a}$ \\
\hline
\end{tabular}


yield/tree (kg)

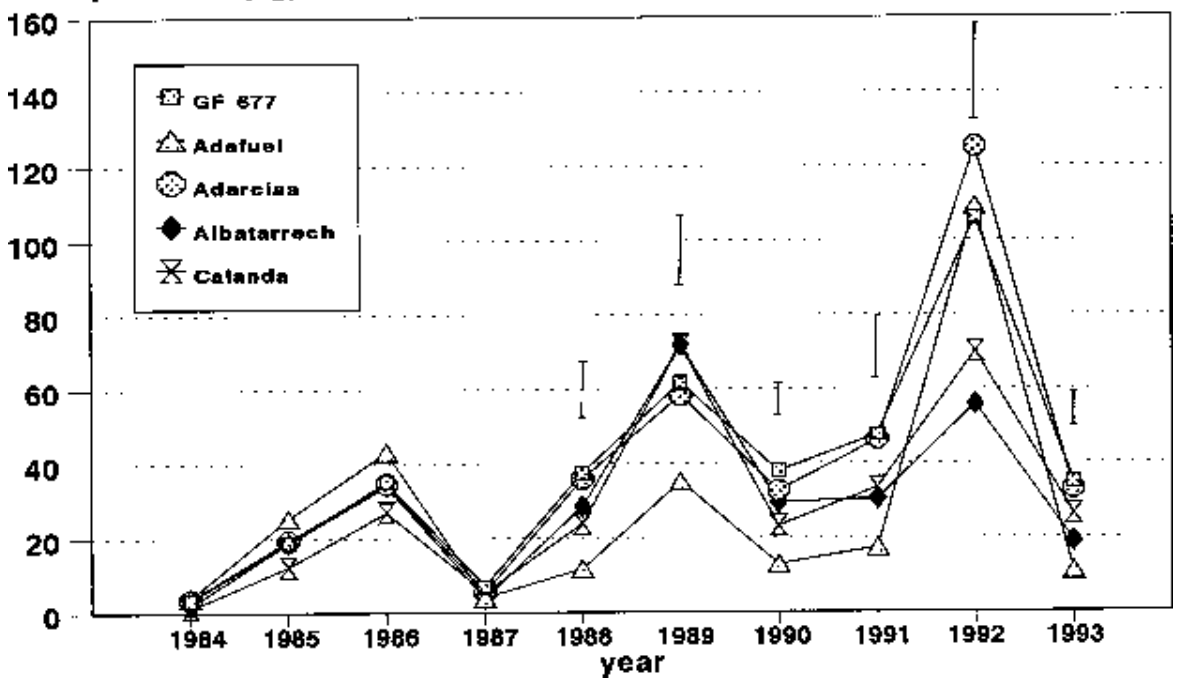

Fig. 1. Yield of 'Loadel' grafted on several peach $x$ almond hybrids, from the third (1984) to the 12th (1993) year of scion growth. Each data point is the mean of five trees. Vertical lines indicate LSD.

Table 2. Rootstock effects on trunk cross-sectional area (TCSA) and yield characteristics of 'Catherina' peach during the first 11 years in the orchard.

\begin{tabular}{|c|c|c|c|c|}
\hline Rootstock & $\begin{array}{l}\text { TCSA } \\
\left(\mathrm{cm}^{2}\right)\end{array}$ & $\begin{array}{l}\text { Cumulative } \\
\text { production } \\
(\mathrm{kg} / \mathrm{tree})\end{array}$ & $\begin{array}{c}\text { Yield } \\
\text { efficiency } \\
\left(\mathrm{kg} \cdot \mathrm{cm}^{-2}\right)\end{array}$ & $\begin{array}{l}\text { Mean } \\
\text { fruit wt } \\
\text { (g) }\end{array}$ \\
\hline Adafuel & $375 b^{z}$ & $264 \mathrm{a}$ & $0.71 \mathrm{a}$ & $144 \mathrm{~b}$ \\
\hline Adarcias & $251 \mathrm{a}$ & $202 \mathrm{a}$ & $0.81 \mathrm{a}$ & $124 \mathrm{a}$ \\
\hline GF 677 & $336 \mathrm{~b}$ & $264 \mathrm{a}$ & $0.79 \mathrm{a}$ & $136 \mathrm{ab}$ \\
\hline
\end{tabular}

${ }^{\mathrm{z}}$ Mean separation within columns at $P \leq 0.05$.

\section{yield/tree (kg)}

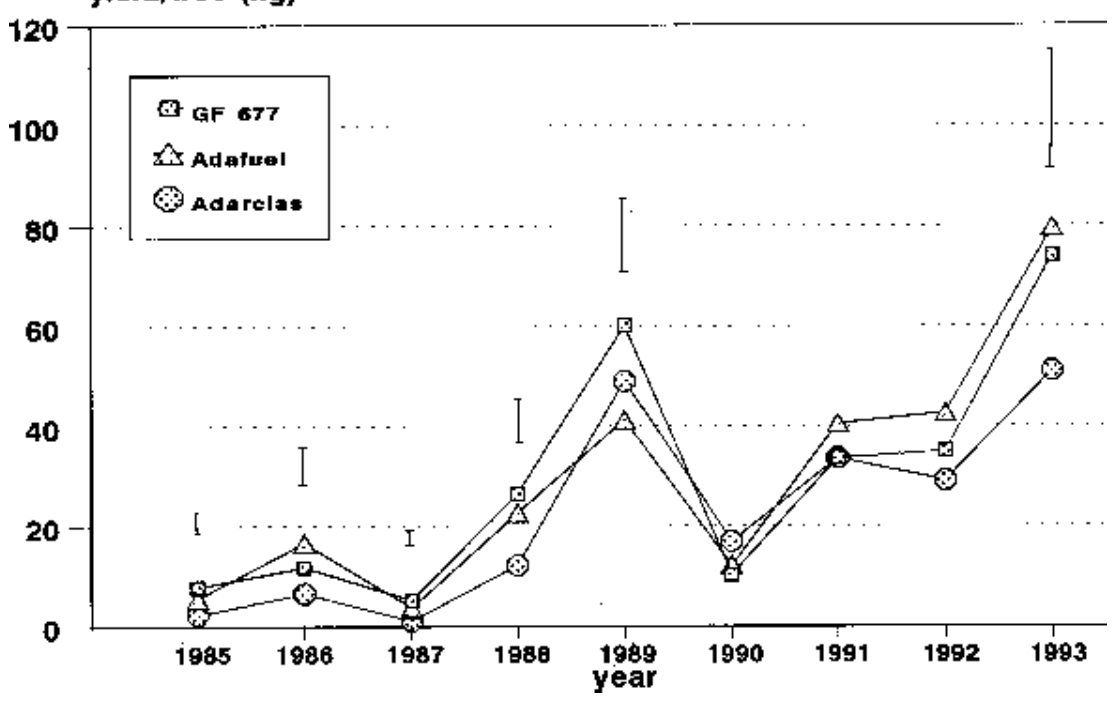

Fig. 2. Yield of 'Catherina' grafted on several peach $x$ almond hybrids, from the third (1985) to the 11th (1993) year of scion growth. Each data point is the mean of five trees. Vertical lines indicate LSD.

Table 3. Rootstock effects on trunk cross-sectional area (TCSA) and yield characteristics of 'Flavortop' nectarine during the first 11 years in the orchard.

\begin{tabular}{lcccc}
\hline \hline & $\begin{array}{c}\text { TCSA } \\
\left(\mathrm{cm}^{2}\right)\end{array}$ & $\begin{array}{c}\text { Cumulative } \\
\text { production } \\
(\mathrm{kg} / \mathrm{tree})\end{array}$ & $\begin{array}{c}\text { Yield } \\
\text { efficiency } \\
\left(\mathrm{kg}^{\circ} \mathrm{cm}^{-2}\right)\end{array}$ & $\begin{array}{c}\text { Mean } \\
\text { fruit wt } \\
(\mathrm{g})\end{array}$ \\
\hline Adafuel & $400 \mathrm{c}^{2}$ & $416 \mathrm{~b}$ & $1.04 \mathrm{a}$ & $152 \mathrm{a}$ \\
Adarcias & $213 \mathrm{a}$ & $297 \mathrm{a}$ & $1.40 \mathrm{~b}$ & $137 \mathrm{a}$ \\
GF 677 & $291 \mathrm{~b}$ & $384 \mathrm{~b}$ & $1.32 \mathrm{~b}$ & $137 \mathrm{a}$ \\
\hline
\end{tabular}

${ }^{\mathrm{z}}$ Mean separation within columns at $P \leq 0.05$. grafted on Adarcias was significantly greater compared to the other hybrids (Table 1). Mean fruit weight of 'Loadel' over 6 years was about equal on Albatarrech and Calanda and higher than on Adarcias, GF 677, or Adafuel (Table 1); however, the latter did not differ significantly from Calanda. Positive correlations were found between rootstock vigor and mean fruit weight in 1989 ( $r=0.86 ; P \leq 0.05)$, but negative correlations were found between crop load and mean fruit weight in 1988, $1991(r=$ $-0.92 ; P \leq 0.05)$, and $1992(r=-0.97 ; P \leq$ $0.01)$.

'Catherina'. For 'Catherina' grafted on Adarcias (Table 2), TCSA was significantly smaller than 'Catherina' on Adafuel and GF 677; although, these two rootstocks did not differing significantly. 'Catherina' on Adarcias showed a $33 \%$ and $25 \%$ reduction in TCSA compared to that on Adafuel and GF 677, respectively. Yields of 'Catherina' grafted on Adafuel and GF 677 were slightly higher than on Adarcias during the first three cropping years (Fig. 2). However, cumulative production was similar for all three by the 11th year of scion growth (Table 2). No significant differences in yield efficiency were found among the three rootstocks. There was a positive correlation between rootstock vigor and crop load in $1993(r=0.99 ; P \leq 0.05)$ similar to the correlation of rootstock vigor and mean fruit weight in 1991 and $1993(r=0.98 ; P \leq 0.05)$. Mean fruit weight (Table 2) was highest when the cultivar was grafted on Adafuel compared to the cultivar on Adarcias, and no differences were detected between GF 677 and the two other rootstocks.

'Flavortop'. For 'Flavortop' (Table 3), TCSA was smallest when grafted on Adarcias, largest on Adafuel, and intermediate on GF 677. On Adarcias, the reduction in TCSA was $47 \%$ and $27 \%$ compared to Adafuel and GF 677, respectively. Yields on Adafuel and GF 677 were only slightly higher than on Adarcias during the first three cropping years (Fig. 3). Cumulative production in the first 11 years of scion growth was similar for Adafuel and GF 677 , but production was significantly lower with Adarcias (Table 3). However, 'Flavortop' grafted on Adarcias or GF 677 had similar yield efficiency, which was higher than on Adafuel. Mean fruit weight was similar for all three rootstocks. Again, a positive correlation between rootstock vigor and mean fruit weight was singled out in 1989, 1991, and $1992(r=$ $0.99 ; P \leq 0.05)$.

\section{Discussion}

Generally, in association with higher yields (Figs. 1-3), significant correlation coefficients were obtained between rootstock vigor and mean fruit weight (positive slope), rootstock vigor and crop load (positive slope), and mean fruit weight and crop load (negative slope).

The higher yield efficiency obtained with Adarcias resulted from its lower vigor. In contrast, the greater vigor of Adafuel reduced the yield efficiency of 'Catherina' and 'Flavortop'. On fertile, deep, and well-irrigated soils, the greater vigor of Adafuel may become 
yleld/tree $(\mathrm{kg})$

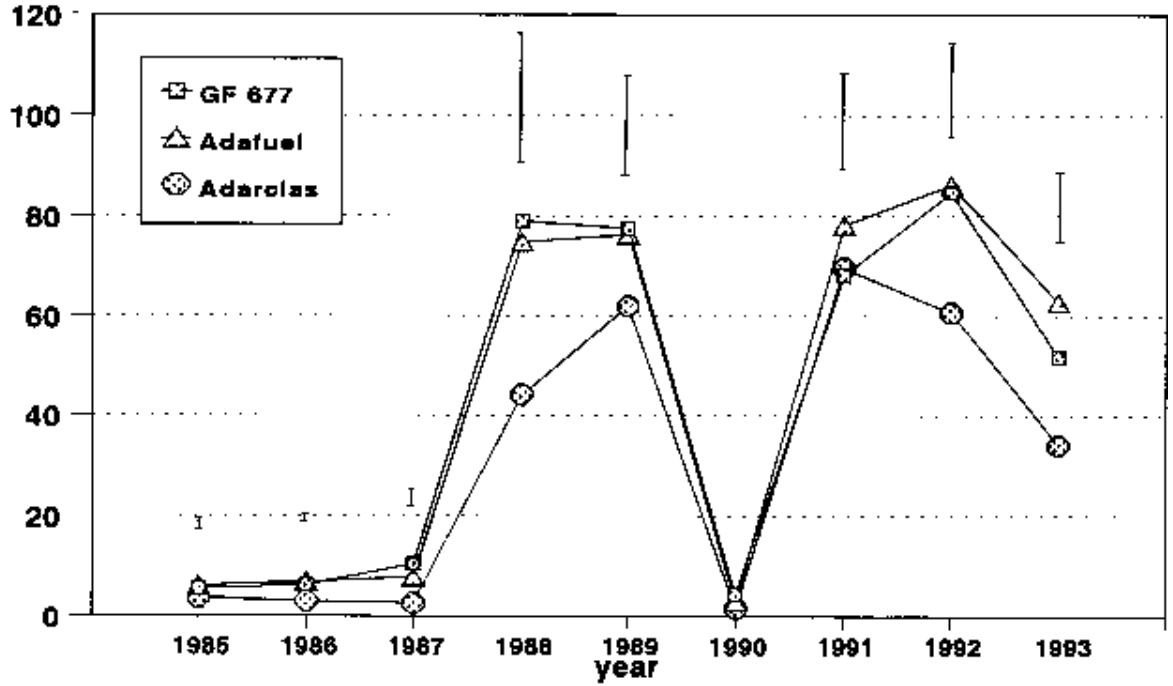

Fig. 3. Yield of 'Flavortop' grafted on several peach $x$ almond hybrids, from the third (1985) to the 11th (1993) year of scion growth. Each data point is the mean of five trees. Vertical lines indicate LSD.

excessive for good orchard practice unless some irrigation and other cultural practices are modified. However, a high vigor level may be advisable when planting on marginal soils or under replanting conditions (Bernhard and Germain, 1975; Cambra, 1990; Kester and Asay, 1986).

Consequently, Adarcias may be suitable for reducing excessive growth of peach cultivars to increase planting density. However, Adafuel (a vigorous rootstock) appears suitable for peach production in poor and calcar- eous soils otherwise not favorable for growing peach. This finding agrees with that of Almaliotis et al. (1993). Further evaluation is advised to test these rootstocks over a wide range of soil conditions.

\section{Literature Cited}

Almaliotis, D.D., A.G. Manganaris, A.D. Simonis, and S.B. Bladenopoulou. 1993. Rootstock effect on performance of 'Maycrest' peach trees under conditions of lime-induced chlorosis. Proc. 7th Intl. Symp. on Iron Nutrition and Interactions in Plants, Zaragoza, Spain, 27 June-2 July, 1993.

Bernhard, R. and E. Germain. 1975. Analyse du mode d'action de porte-greffes vigoreux: Cas des hybrides amandier $x$ pêcher, porte-greffes du pêcher. Ann. Amélior. Plantes 25:321-336.

Bernhard, R. and C. Grasselly. 1959. Les pruniers porte-greffes du pêcher. Journées Fruitières et Maraichéres d'Avignon 75-100.

Bernhard, R. and C. Grasselly. 1981. Les pêchers X amandiers. L'Arboriculture Fruitière 328:3742.

Cambra, R. 1990. 'Adafuel', an almond x peach hybrid rootstock. HortScience 25:584.

Egilla, J.N. and D.H. Byrne. 1989. The search for peach rootstocks tolerant to alkalinity. Fruit Var. J. 43:7-11.

Guerriero, R., F.Loreti, and R. Massai. 1988. Evaluation of new peach rootstocks for high-density planting systems. HortScience 23:117-118.

Kester, D.E. and R.N. Asay. 1986. 'Hansen 2168' and 'Hansen 536': Two new Prunus rootstock clones. HortScience 21:331-332.

Loreti, F., R. Guerriero, R. Massai, and M. Matteucci. 1989. Comparative trial with two newly-selected peach rootstocks. Acta Hort. 254:67-72.

Moreno, M.A. and R. Cambra. 1994. 'Adarcias': An almond $x$ peach hybrid rootstock. HortScience 8:925.

Norusis, M.J. 1986. Statistical package for the social sciences/PC+. SPSS, Chicago.

Proebsting, E.L., Jr. 1958. A quantitative evaluation of the effects of fruiting on growth of Elberta peach trees. Proc. Amer. Soc. Hort. Sci. 71:103109.

Syrgiannidis, G. 1985. Control of iron chlorosis and replant diseases in peach by using the GF 677 rootstock. Acta Hort. 173:383-388. 